\title{
A Multi-touch Interface for Enhancing Collaborative UML Diagramming
}

\begin{abstract}
Multi-touch interfaces facilitate collaborative learning and, thus, represent a promising educational technology. Their ability to synchronously accommodate multiple users is an advantage in co-located collaborative design tasks. This paper explores the multi-touch interface's potential in collaborative Unified Modelling Language (UML) diagramming by comparing it to a PC-based tool. The results of the study demonstrate that the use of the multi-touch table enables an increase in the equity of participation, enhanced collaboration amongst team members, and the facilitation of parallel-participative design.

\section{Author Keywords \\ Equity of participation; Multi-touch table; Parallel- participative design; Software design; Unified Modelling Language}

\section{ACM Classification Keywords}

H.5.3 Group and organization interfaces (e.g. HCI): Synchronous interaction.

\section{INTRODUCTION}

Collaborative learning has become a popular in computer education and advantages of collaborative learning over individualised learning have been studied in literature (Baghaei et al., 2007; Laakso et al., 2010). Collaborative problem-solving, for instance, has numerous advantages. For example, it facilitates co-operation amongst students, encourages them to ask questions, and even encourages them to develop and consolidate their own knowledge (Webb et al., 1995; Soller 2001; Rummel et al., 2005).

In the realm of collaborative software design, multi-touch surfaces have recently received significant attention, as this technology offers the potential of helping ease humancomputer interaction. For instance, the ability of shared displays, like tabletops, to accommodate multiple users synchronously has applications in collaborative learning (Han 2005; Higgins et al., 2011). Thus, multi-touch interfaces promote collaboration in a local environment, allowing ideas and solutions to be exchanged simply and without technological impediments. Furthermore, the

Permission to make digital or hard copies of all or part of this work for personal or classroom use is granted without fee provided that copies are not made or distributed for profit or commercial advantage and that copies bear this notice and the full citation on the first page. To copy otherwise, or republish, to post on servers or to redistribute to lists, requires prior specific permission and/or a fee.

OZCHI'12, November 26-30, 2012, Melbourne, Victoria, Australia.

Copyright 2012 ACM 978-1-4503-1438-1/12/11...\$10.00. technology is capable of improving students' communication skills and encouraging co-operation (Ha et al., 2006).

Multi-touch surfaces can offer small groups the opportunity to collaborate locally (Rick et al., 2009), thus, the research has demonstrated that multi-touch environments can improve collaborative work. Multitouch table increases group task performance, unlike single touch tabletop (Harris et al, 2009). However, studies into the potential of multi-touch tables in aiding co-located collaboration in software design using Unified Modelling Language (UML) have been lacking.

UML is used as the principal notation in software analysis and design (Baghaei et al., 2007). Objectoriented (OO) analysis and design is a difficult task, requiring familiarity with requirements analysis, design, and UML. The texts of the problem are often vague and deficient, requiring students to be experienced for analysis to be successful. The UML language itself is complex, and students face many problems in seeking to become proficient in this language. Furthermore, UML, similar to most design tasks, is an ill-defined process, and there are often multiple solutions of equal validity for solving the problem presented by a task. Furthermore, UML is open to discussion because of the open-ended nature of the language. Thus, this paper explores the multi-touch interface's potential in collaborative software design using UML, by comparing it to a PC-based tool used for similar purposes.

Several research attempts have been made to facilitate collaborative software design using UML, such as COLLECT-UML (Baghaei et al., 2006; Baghaei et al., 2007), CoLeMo (Chen et al., 2006), CAMEL (Cataldo et al., 2009), and AUTO-COLLEAGUE (Tourtoglou et al., 2008). Unlike COLLECT-UML and CoLeMo, the AUTOCOLLEAGUE system does not support collaborative drawing for UML diagrams; instead, it relies on a chat system as the collaborative tool. What all these systems have in common, however, is that they have been designed solely to aid in distributed collaborative work, and they are not face-to-face systems. While these systems exist, we have not found any evidence of a multi-touch table based editor for UML diagramming.

\section{COMPARATIVE STUDY}

We developed a multi-touch collaborative UML editor called "MT-CollabUML" (Basheri et al., 2012) in order to facilitate face-to-face collaborative software design. Furthermore, in our study we used MT-CollabUML in 
both multi-touch and PC-based environments to ensure that the variables remained the same.

\section{Participants}

The participants in the study were 18 master's students (14 females and 4 males), between the ages of 20 and 28 years, who were all familiar with collaborative software design using UML and had also completed the "Software Engineering for the Internet" module of their course. For the purposes of the research, these 18 participants were grouped into 9 pairs.

\section{Experiment design}

The research involved a within-subject experiment designed to study how participants in collaborative design use PCs as compared to the multi-touch table. The purpose of this experiment was to examine the differences in the quality of the collaborative design process between conditions. This was done by examining the similarities and differences in terms of the qualitative behaviour of the nine pairs, who were tasked with creating UML-state diagrams. To ensure the study's validity, we compared the use of the MT-CollabUML tool in two similar design tasks of similar complexity and difficulty in both the PC-based and multi-touch environments.

Repeated measures design was conducted in this experiment to help keep the variability low. The nine groups of students was arranged into group of pairs; for every pair of groups, we gave one group a UML design task and asked them to complete it using the MTCollabUML tool in PC-based "Figure 1". The other group was asked to complete the same task using the MTCollabUML tool on multi-touch table based. Then the groups switched and were asked to complete the second task using PC and multi-touch conditions "Figure 2".

\section{Procedure}

As a preliminary procedure, all participants were trained in the basics of the MT-CollabUML tool in both the multi-touch and PC-based versions. There was no time limit imposed on the groups to complete the tasks. For analysis, the UML diagramming activities for both the PC-based and multi-touch environments were video recorded using two video cameras focused on the tables from different angles to ensure that both group members were recorded.

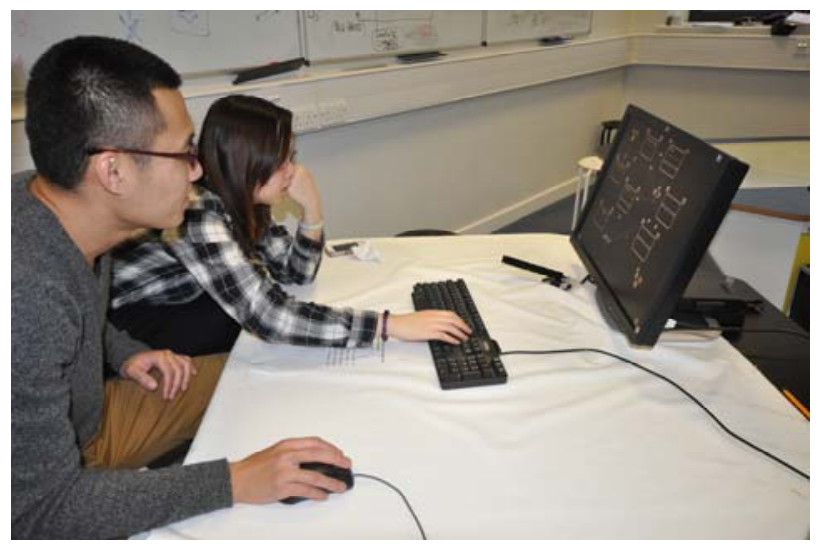

Figure 1. PC-based collaborative UML diagramming

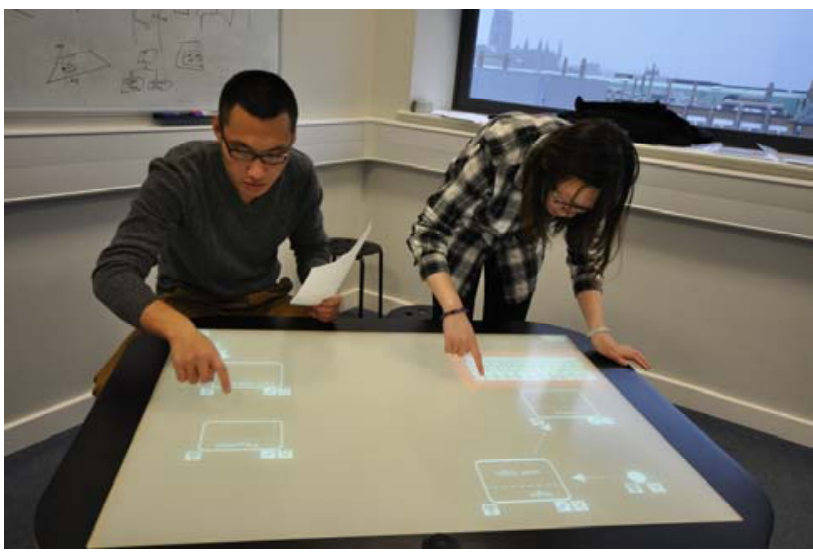

Figure 2. Multi-touch table based collaborative UML diagramming

The process of creating UML state diagrams involved design activities such as adding start nodes, state nodes, condition nodes, end nodes, and making links and annotations. The PC-based environment contained a 24inch LCD screen and required the participants to share a mouse and keyboard, as shown in Figure 1, while the multi-touch table-based environment involved digital keyboards and demanded the use of hand gestures as opposed to a mouse.

\section{STUDY FINDINGS AND DISCUSSION}

The study aimed at determining the benefits of using a multi-touch table in order to facilitate teamwork amongst students and improve the design process.

\section{Equity of Participation}

The interaction in both the multi-touch and PC-based conditions involved common interactions which were counted, such as adding nodes, deleting nodes, adding text, linking nodes, unlinking nodes, editing text, and resizing and moving nodes. We followed Harris et al.'s (2009) work and calculated the interactions per minute for each participant under both conditions. The results indicated that there were more interactions in the multitouch environment $(\mathrm{M}=3.53, \mathrm{SD}=1.02)$ than in the PCbased environment $(\mathrm{M}=3.37, \mathrm{SD}=2.10)$. However, the difference between conditions was not statistically significant $(p=0.67)$ based on Wilcoxon Signed Ranks test.

Furthermore, the Gini coefficient was applied in order to measure the relative contribution of the individuals within each group. "The Gini Coefficient sums the deviation from equal participation for all members of a group, normalized by the maximum possible value of this deviation" (Harris et al. 2009). The values of the Gini coefficient ranged from 0 to 1 , where a large score represented lower equity and a low score reflected greater equity. The results indicated that the equity of participation in the multi-touch table condition $(\mathrm{M}=0.08$, $\mathrm{SD}=0.1$ ) was greater than that of the PC-based condition $(\mathrm{M}=0.23, \mathrm{SD}=0.11)$ and the difference between conditions was statistically significant $(p<0.05)$ based on Wilcoxon Signed Ranks test.

Individual contributions to the task included different design activities, such as adding and deleting nodes, 
adding and editing text, linking and unlinking nodes, and moving nodes. The proportion of the contribution of the group members to the task in the multi-touch table and PC conditions is shown in Figures 3 and 4, respectively. As we can see, in most cases, one of the subjects contributed more than the other in the PC-based condition, whereas the individuals contributed almost equally in the task in the multi-touch condition.

\section{Sequential-participative vs. Parallel-participative}

Working in parallelism manner increases productivity, reduces anonymity and overcomes production blocking. However, PC-based face-to-face collaboration does not support parallelism actions (Hilliges et al, 2007).

In sequential-participative design, the collaborative design is carried out in a sequential manner, and in parallel-participative design, it is carried out in a parallel manner. The qualitative analysis of the design process shows that in the PC-based condition, the groups used a sequential-participative design technique. This is perhaps because of the nature of sharing a PC, as it allows only one action at a time. However, in the multi-touch condition, the groups used a parallel-participative design technique, as the multi-touch table allowed the participants to carry out multiple actions simultaneously. To elaborate, one of the groups (Group 3) was chosen as a case study to describe the differences between the two conditions in this context.

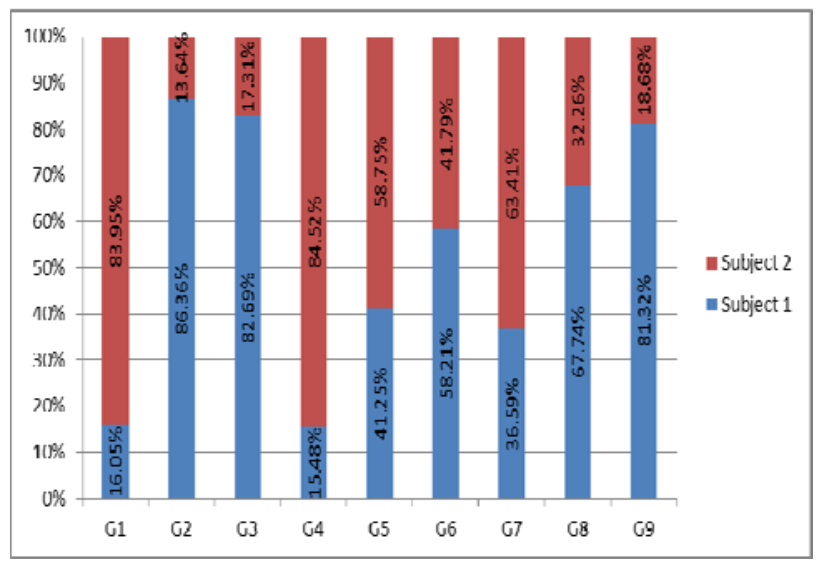

Figure 3. The contribution of individuals to the task in PC based (in percentage).

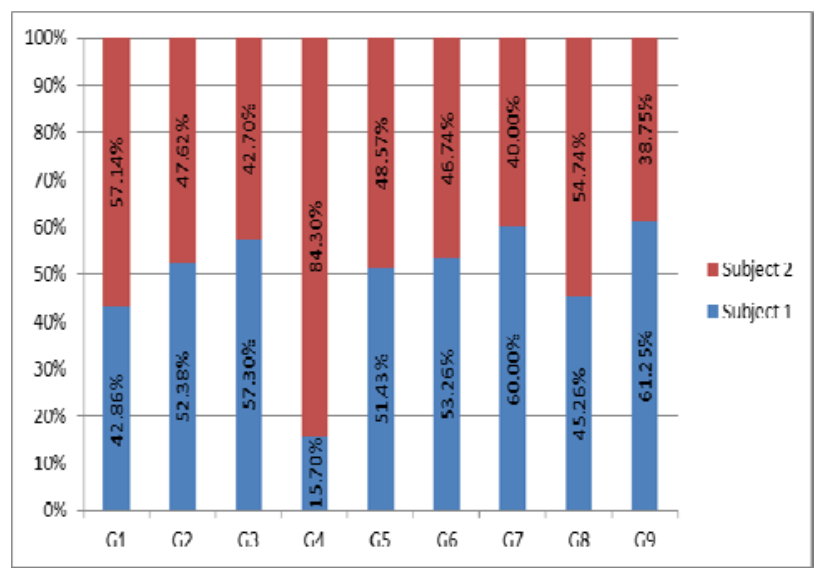

Figure 4. The contribution of individuals to the task in Multi-touch based (in percentage).
Figures 5 and 6 display the timeline of Group 3's design activities for the individuals in both conditions. In the PC setting shown in Figure 5, when Person 5 (P5) was engaged in typing (03:09), P6 was not able to contribute physically to the task. On the other hand, in the multitouch setting (Figure 6), when P5 was typing (06:14), P6 was able to use another keyboard to type as well (06:25).

Figure 7 is a screenshot of minute six. It shows that the participants used two keyboards to type in two different nodes at the same time. In the multi-touch based condition, the participants were able to perform multiple actions synchronously without hindering each other. Thus, the multi-touch MT-CollabUML application allowed for an effective level of collaboration in the collaborative design process, and it encouraged more participation from the group members.

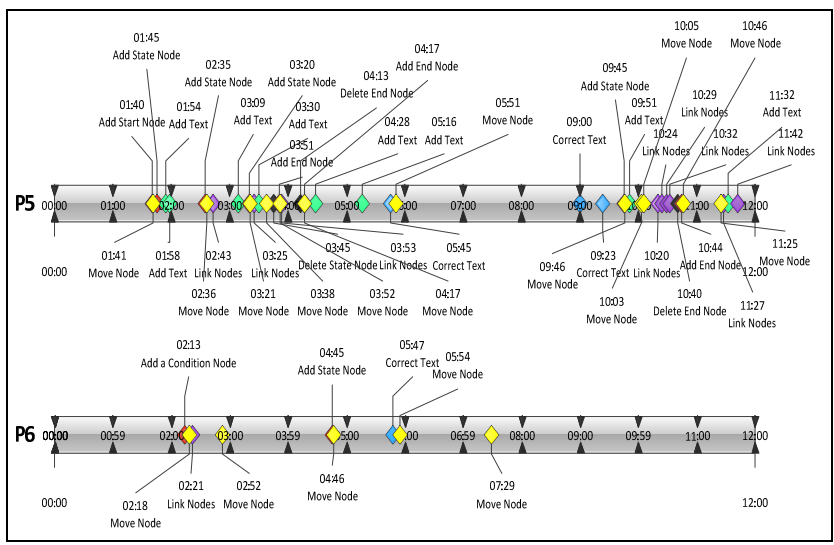

Figure 5. Timeline of individual contribution to the task in PC condition (Group 3)

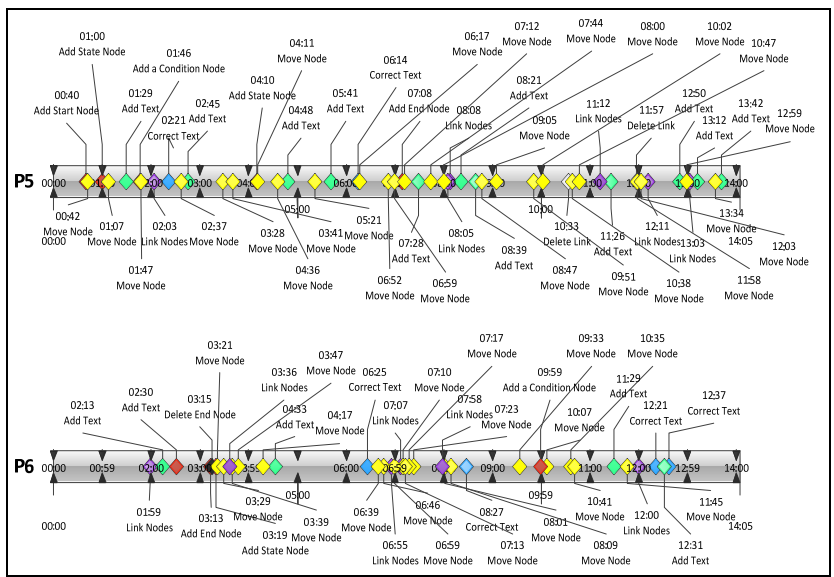

Figure 6. Timeline of individual contribution to the task in Multitouch condition (Group 3)

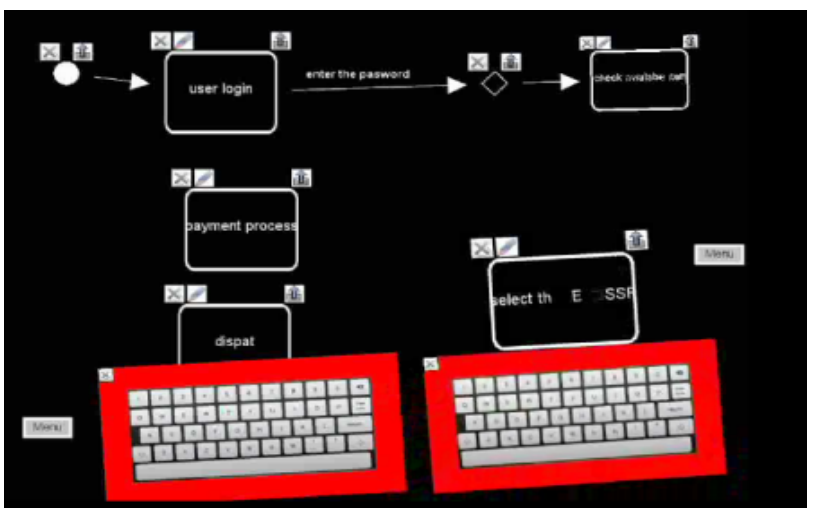

Figure 7. Screenshot of minute 6 in multi-touch (Group 3) 


\section{CONCLUSIONS}

In this paper, we examined the differences in collaborative software design amongst groups of students working in PC-based and multi-touch table-based conditions. We hypothesised that the multi-touch table would increase the effectiveness of the collaborative process.

The results indicate the benefit of using the multi-touch MT-CollabUML as opposed to the PC-based version in enhancing collaborative software design. The multi-touch environment increases the equity of participation and encourages parallel-participative design. More research should be done on multi-touch based designs to further explore the benefits of using these interfaces.

\section{ACKNOWLEDGMENTS}

The authors would like to acknowledge that the hardware for this research was provided by the EPSRC under grant research number RES-139-25-0400.

\section{REFERENCES}

Baghaei, N. and Mitrovic, A. A constraint-based collaborative environment for learning UML class diagrams. Lecture notes in Computer Science. M. Ikeda, K.D. Ashley and T.W. Chan, Springer Berlin / Heidelberg. Springer Berlin / Heidelberg (2006), 176-186.

Baghaei, N., Mitrovic, A. and Irwin, W. Supporting collaborative learning and problem-solving in a constraintbased CSCL environment for UML class diagrams. International Journal of Computer-Supported Collaborative Learning (2007), 159-190.

Basheri, M. and Burd, L. Exploring the significance of multitouch tables in enhancing collaborative software design using UML. Frontiers in Education Conference, Seattle, Washington, USA (in press) (2012).

Cataldo, M., Shelton, C., Yongjoon, C., Yun-Yin, H., Ramesh, V., Saini, D. and Liang-Yun, W. CAMEL: A tool for collaborative distributed software design. Global Software Engineering, 2009. ICGSE 2009. Fourth IEEE International Conference (2009).

Chen, W., Pedersen, R. and Pettersen, O. CoLeMo: A collaborative learning environment for UML modelling. Interactive Learning Environments (2006), 17.

Ha, V., Inkpen, K.M., Mandryk, R.L. and Whalen, T. Direct intentions: The effects of input devices on collaboration around a tabletop display. Proceedings of the First IEEE International Workshop on Horizontal Interactive HumanComputer Systems (2006).
Han, J. Low-cost multi-touch sensing through frustrated total internal reflection. Proceedings of the 18th Annual ACM Symposium on User Interface Software and Technology, Seattle, WA, USA, ACM (2005).

Harris, A., Rick, J., Bonnett, V., Yuill, N., Fleck, R., Marshall, P. and Rogers, Y. Around the table: Are multiple-touch surfaces better than single-touch for children's collaborative interactions? Proceedings of the 9th international conference on Computer supported collaborative learning. Rhodes, Greece, International Society of the Learning Sciences (2009), 335-344.

Higgins, S., Mercier, E., Burd, L. and Joyce-Gibbons, A. Multitouch tables and collaborative learning. British Journal of Educational Technology (2011).

Hilliges, O., L. Terrenghi, S. Boring, D. Kim, H. Richter and A. Butz. Designing for collaborative creative problem solving. Proceedings of the 6th ACM SIGCHI conference on Creativity \& cognition. Washington, DC, USA, ACM (2007),137-146.

Laakso, M.-J., Myller, N., Korhonen, A., Cordeiro, J. and Filipe, J. Interaction promotes collaboration and learning: Video analysis of algorithm visualization use during collaborative learning. Web Information Systems and Technologies. W. Aalst, J. Mylopoulos, M. Rosemann, M.J. Shaw and C. Szyperski, Springer Berlin Heidelberg. Springer Berlin Heidelberg (2010), 198-211.

Rick, J., Harris, A., Marshall, P., Fleck, R., Yuill, N. and Rogers, Y. Children designing together on a multi-touch tabletop: An analysis of spatial orientation and user interactions. Proceedings of the 8th International Conference on Interaction Design and Children. Como, Italy, ACM (2009).

Rummel, N. and Spada, H. Learning to collaborate: An instructional approach to promoting collaborative problem solving in computer-mediated settings. Journal of the Learning Sciences (2005), 201-241.

Soller, A. Supporting social interaction in an intelligent collaborative learning system. International Journal of Artificial Intelligence in Education (IJAIED) (2001), 40-62.

Tourtoglou, K., Virvou, M., Tsihrintzis, G., Howlett, R. and Jain, L. User stereotypes concerning cognitive, personality and performance issues in a collaborative learning environment for UML. Studies in Computational Intelligence. G.A. Tsihrintzis, M. Virvou, R.J. Howlett and L.C. Jain, Springer Berlin / Heidelberg. Springer Berlin / Heidelberg (2008), 385-394.

Webb, N.M., Troper, J.D. and Fall, R. Constructive activity and learning in collaborative small groups. Journal of educational psychology (1995), 406-423. 